\title{
The Jackson Laboratory Cancer Center
}

National Cancer Institute

\section{Source}

National Cancer Institute. The Jackson Laboratory Cancer Center. NCI Thesaurus. Code C39529.

The Jackson Laboratory Cancer Center conducts basic research using the mouse as a research tool. Its mission is to discover the genetic basis for preventing, treating, and curing human disease, and to enable broader research in the global biomedical community. This independent, nonprofit organization was designated as an $\mathrm{NCl}$ cancer center in 1983. 